\title{
Concepçôes de saúde, trabalho docente e o Pró-Saúde: nos caminhos da hermenêutica...
}

\section{| ${ }^{1}$ Adriani Cristiani Stanga, ${ }^{2}$ Ricardo Rezer |}

Resumo: O objetivo desta investigação é compreender as concepções de saúde que orientam o trabalho dos professores articuladores inseridos no Pró-Saúde. Os caminhos teórico-metodológicos foram perspectivados a partir de uma orientação hermenêutica. O trabalho de campo contou com as contribuiçôes de oito professores do Pró-Saúde II da Unochapecó. O instrumento utilizado foi uma entrevista semiestruturada. $\mathrm{O}$ processo interpretativo foi elaborado a partir da fundamentação hermenêutica de Gadamer e Habermas e embasado a partir da análise temática proposta por Minayo. As concepçōes de saúde identificadas estão fortemente vinculadas à noção de bem-estar. As referências com as quais os colaboradores trabalham no cotidiano são: documentos da Organização Mundial da Saúde, Carta de Ottawa, a Constituição Federal Brasileira e as políticas implementadas pelo Ministério da Saúde. As diretrizes orientadoras do Pró-Saúde, segundo os colaboradores, permitiram discutir com mais propriedade o conceito de saúde ampliada, o que favorece, em certa medida, a sistematização e a organização das intervenções docentes para a efetivação da formação inicial em saúde. Portanto, mais do que "definir" ou evidenciar uma ou algumas concepções de saúde, entendemos que o mais importante é manter em aberto a discussão sobre os "sentidos de saúde" com os quais vamos atuar junto com outros, em diferentes processos de intervenção.

\footnotetext{
1 Universidade Comunitária da Região de Chapecó. Área de Ciências da Saúde. Chapecó-SC, Brasil. Endereço eletrônico: drika.07@unochapeco.edu.br

2 Universidade Comunitária da Região de Chapecó. Programa de Pós-Graduação em Ciências da Saúde. Chapecó-SC, Brasil. Endereço eletrônico: rrezer@ unochapeco.edu.br
}

> Palavras-chave: hermenêutica; concepções de saúde; Pró-Saúde. 


\section{Considerações iniciais}

Ao longo dos anos, a compreensão sobre o que "é" saúde vem apresentando diversos sentidos e significados e tornando inesgotável a discussão sobre o tema, especialmente devido à subjetividade e circularidade das ações humanas, historicamente edificadas em meio a diferentes interesses e relações de poder.

Dialogar sobre compreensões de saúde representa um esforço necessário para dotar de sentido, no mundo comum, diferentes interpretações do conhecimento articuladas à reflexão sobre o próprio papel da ciência e sua vinculação com o senso comum frente a diferentes visões de mundo. Reconhecer essa discussão proporciona compreender melhor aspectos problemáticos no campo da saúde e aproximar possíveis soluções através de questionamentos que "tensionam” o movimento do saber nesse campo.

Nessa perspectiva, este estudo é um recorte oriundo de uma dissertação de mestrado realizada junto ao Programa de Pós-Graduação em Ciências da Saúde da Universidade Comunitária da Região de Chapecó (Unochapecó) entre 2012 e 2014. Tal esforço representa uma possibilidade de aprofundamento sobre as compreensões de saúde apresentadas pelos professores que atuam na formação inicial na denominada "Área da Saúde", a partir de uma reflexão filosófica que busca interpretar como esse entendimento interfere na sua intervenção.

A própria discussão sobre o que "é” saúde se faz necessária para uma compreensão mais ampla sobre por que determinadas práticas ou intervenções são como são, ou por que elas se dão de uma forma e não de outra. Na educação superior, torna-se extremamente relevante compreender o sentido de determinadas intervenções a partir da perspectiva dos docentes, enquanto conhecimento e entendimento dos elementos que envolvem a formação inicial e sua interpretação sobre saúde.

A partir da implementação do Sistema Único de Saúde (SUS), ações desenvolvidas conjuntamente pelo Ministério da Saúde e pelo Ministério da Educação criam o Programa Nacional de Reorientação da Formação Profissional em Saúde (Pró-Saúde), um conjunto de dispositivos e estratégias que tende a qualificar e atualizar a forma de condução sobre as intervenções voltadas à saúde na educação superior e à educação em saúde.

Partindo disso, o objetivo principal deste artigo consistiu em compreender, pautando-se em uma orientação hermenêutica, as concepções de saúde que 
orientam o trabalho dos professores articuladores inseridos no Pró-Saúde. A seguir, apresentaremos os caminhos teórico-metodológicos de nossa investigação.

\section{Caminhos teórico-metodológicos}

Trata-se de um estudo descritivo, para o qual destacamos que a hermenêutica não se deu como um referencial exclusivamente metodológico, mas como uma possibilidade interpretativa de mundo, presente nas diversas etapas da investigação. Nesse sentido, o estudo pretende contribuir no processo de compreender e interpretar os elementos e problemáticas que se apresentam no cotidiano, a partir do diálogo como pressuposto para a produção de acordos em um mundo comum. A pesquisa contemplou os seguintes momentos:

Aproximação com o grupo de colaboradores: a escolha do grupo de colaboradores ocorreu de forma intencional e voluntária, tendo em vista suas aproximações com a formação inicial em saúde. Foi necessário definir alguns critérios que permitissem a composição do grupo: a) professores que exercem a docência no âmbito da Unochapecó; b) que estão na formação inicial em saúde; e c) que faziam parte das atividades do Pró-Saúde no ano de 2013, na condição de professores articuladores de curso. Dos onze professores inicialmente convidados, participaram da pesquisa oito colaboradores, todos do gênero feminino, com idade entre 33 e 50 anos e cujo tempo de formação era de 11 a 26 anos de carreira. Sobre o tempo de atividades na Unochapecó, o grupo apresentou entre 3 e 18 anos de trabalho, com uma carga horária entre 20 e 40 horas semanais. Em relação à titulação, o grupo apresentou três especialistas, que estavam cursando programa de Mestrado, três colaboradoras com titulação de Mestre, uma delas com o Doutorado em andamento, e duas doutoras.

Instrumento de pesquisa - a entrevista semiestruturada: todas as entrevistas aconteceram pelo agendamento prévio com cada colaborador, ocorrendo de forma voluntária e individual, sendo posteriormente gravadas e transcritas. Nesse processo, recorremos ao Termo de Consentimento para Uso de Imagem e Voz e o Termo de Consentimento Livre e Esclarecido, de acordo com a Resolução n ${ }^{\circ}$ 466/2012. A construção de blocos temáticos orientadores sistematizados em um roteiro prévio colaborou para o desenvolvimento das entrevistas, considerando: (a) Experiências no processo de formação; (b) Concepções de Saúde; (c) A importância de discussões conceituais como referência para intervenção; e (d) 
A concepção de saúde expressa nos Projetos Pedagógicos (PP) dos cursos de graduação e do Pró-Saúde.

O trabalho de campo: aprovada pelo Comitê de Ética em Pesquisa (CEP Unochapecó), sob o parecer consubstanciado $n^{\circ}$ 257/13, a pesquisa foi conduzida dentro de padrões éticos exigidos pela Comissão Nacional de Ética em Pesquisa / Conselho Nacional de Saúde / Ministério da Saúde (CONEP/CNS/MS), ao disposto na Resolução CONEP no 466/12. A ordem das entrevistas ocorreu conforme a disponibilidade de agenda de cada colaborador. A fim de garantir o sigilo e o anonimato, cada colaborador foi identificado por um nome popular de espécie de árvore: Carvalho, Copaíba, Figueira, Buriti, Jacarandá, Jequitibá, Salgueiro e Ypê.

$O$ processo interpretativo: $\mathrm{O}$ processo de interpretação deste estudo se desenvolveu ao longo de toda sua construção, levando em consideração os elementos oriundos das entrevistas realizadas, o referencial teórico da investigação e as experiências dos pesquisadores na discussão proposta. Nesse sentido, o referencial hermenêutico foi fundamental como possibilidade para a compreensão de argumentos que permitem o estabelecimento de sentidos e significados na dinâmica do diálogo e na sua capacidade de acordos ou tensionamentos. Para análise e interpretação dos dados, utilizamos a análise temática (MINAYO, 2010), por considerá-la uma perspectiva efetiva de interpretação coerente com o referencial hermenêutico adotado. A análise foi realizada em três etapas: préanálise, exploração do material e interpretação dos referenciais do trabalho de campo. A seguir, apresentaremos os principais achados desta investigação.

\section{Compreensões de saúde, processos pedagógicos e a formação inicial...}

Todo artigo derivado de uma pesquisa representa um recorte do processo investigativo, esforço que exige cuidado na estratégia de selecionar os aspectos considerados de maior relevância. A seguir, iremos apresentar as principais sínteses edificadas ao longo do processo investigativo.

\section{Concepções de saúde dos colaboradores: problematizando (in) compreensões na formação profissional...}

A discussão que envolve a temática da saúde exige, dentre outros fatores, uma compreensão ampliada sobre as múltiplas dimensionalidades inerentes a essa 
condição humana complexa. Desse modo, a partir da ótica dos colaboradores, as concepções de saúde (e doença) mais discursadas se referiram à: (a) saúde compreendida como bem-estar, (b) doença como causa biológica e (c) realidade do sujeito.

Em primeira instância, podemos observar a referência ao bem-estar, tal como conceituado pela Organização Mundial da Saúde (OMS). A fala de Copaíba representa bem essa tendência, ao afirmar que saúde seria:

[...] uma definição bem complexa, porque não é só ausência de doenças, pelo próprio termo da OMS, mas envolve várias áreas da vida. Percebo que hoje é um pouco difícil dizer que a gente tem saúde, porque você envolve não só essa ausência de doenças, mas você tem o bem-estar físico, emocional, no trabalho, lazer.

Além dessa aproximação com os conceitos da OMS, a noção de bem-estar também encontra referência a partir da Carta de Ottawa. Também foram mencionados por Ypê elementos que denotam essa compreensão:

Saúde é bem-estar, numa perspectiva de que, para ter bem-estar eu preciso ter condições adequadas de trabalho, preciso ter acesso aos serviços de saúde, preciso de lazer, preciso ter tempo, preciso ter dinheiro, preciso ter comida adequada e de qualidade. Saúde é essa possibilidade de estar bem no espaço onde vivo.

A partir disso, e pela forte presença do termo "bem-estar" no discurso docente, é possível postular alguns argumentos que permitem refletir sobre tal assertiva. Habermas nos fornece elementos para a reflexão quando incorpora a ética do discurso, em que uma norma só deve pretender validez quando todos os que possam ser concernidos por ela cheguem (ou possam chegar), enquanto participantes de um discurso prático, a um acordo quanto à validez dessa norma (REESE-SCHÄFER, 2008). Ou seja, a idealização de que o conceito de bemestar trazido por pela OMS, pelas Cartas de Promoção e outras prerrogativas legislativas determinando o que é saúde, estão impregnados no conceito daquilo que se conhece por saúde na percepção docente que coadunam e transferem para si a validade enquanto um conhecimento comum.

Por um lado, percebemos nisso um avanço, pois são referências que possuem, a seu modo, sentido e fundamentação. Por outro, ao que parece, o problema está na ausência ou desconsideração da reflexão sobre esse sentido, aspecto que retomaremos mais à frente.

A participação social em que estamos inseridos também reforça algumas presunçôes assumidas no mundo de vida (Lebenswelt). Reese-Schäfer (2008), 
ao citar Habermas, argumenta que linguagem e cultura, enquanto elementos de fundo do mundo da vida, têm que ser, de certa forma, sempre já pressupostas, pois elas são o próprio sistema de referência de entendimento. A partir dos sujeitos participantes da ação, a sociedade é o mundo de vida de um grupo social. $\mathrm{Ou}$ seja, podemos assumir a prerrogativa de protagonistas nos acordos produzidos no mundo humano, considerando certamente os limites e paradoxos de um empreendimento como esse.

E isso se dá a partir de nossos preconceitos. Gadamer (1997) retoma a noção de preconceito como uma dimensão importante para o conhecimento. A palavra preconceito se divide, etimologicamente, em pré-conceito ou pré-julgamento. Nesse caso, o julgamento não é possível sem o "pré" que o acompanha. Todos os julgamentos estão condicionados pelos pré-julgamentos. Trata-se é um sentido mais antigo, pré-moderno, para o qual Gadamer quer chamar a atenção. No cotidiano, o preconceito é comumente concebido como um julgamento não reflexivo ou como um raciocínio precipitado, resultando na intolerância de opinião puramente subjetiva ou repetição constante de sabedoria acumulada, como evidencia Lawn (2010). Assim, concepções de saúde também são determinadas pelas formulaçôes que cada sujeito carrega consigo, que podem ser ampliadas pelas experiências no decorrer de nossa história.

Gadamer (2011, p. 136) afirma que a noção de "pessoa saudável" se sustenta por uma camada mais profunda de nosso inconsciente, por uma espécie de bemestar "indizível”. Assim, afirma que, quando nos sentimos saudáveis, estamos, na realidade, entregues àquilo que, respectivamente, está aí para nós, e todos sabemos o quão fácil qualquer mal-estar e, sobretudo, uma dor podem perturbar esse sublime estado de despertar.

Nessa direção, o colaborador Carvalho afirma que doença "é algo que precisa ser curado, que dói, que incomoda, que causa dor", reforçado por Salgueiro, "a doença é uma enfermidade que vem desde uma psique até a parte física [...] então, ela pode ser tanto uma situação visível quanto apenas sentida, relatada pela pessoa enferma".

Ao longo do diálogo, percebemos, por um lado, avanços na questão investigada. Os colaboradores declaram sua compreensão evidenciando um esforço em destacar elementos da saúde-doença como processo, como algo em movimento. Por outro lado, ainda se percebe de forma implícita, concepções de 
saúde e doença realçadas pelo modelo dicotômico. Enraizado pela racionalidade instrumental, este compreende as partes separadas daquilo que constitui a totalidade, assim como foi concebida a dualidade mente e corpo. Essa última é evidenciada na fala de Jacarandá, quando diz que doença é "sempre quando tem uma alteração da nossa homeostasia, nosso equilíbrio dinâmico e que de alguma forma, o organismo, ele não consegue recuperá-lo”.

De sua parte, Ayres (2007) afirma que, fazer equivaler saúde e doença a situações polares de uma coisa, identificadas segundo uma mesma racionalidade, é tão limitante para a adequada compreensão dessas duas construções discursivas e das práticas a elas relacionadas quanto negar as estreitas relações que guardam uma com a outra na vida cotidiana.

Nesse contexto, fortemente vinculadas ao modelo hegemônico atual da Medicina (modelo biomédico), a explicação da doença advinda do tratamento do corpo em partes cada vez menores e a compreensão do corpo como um constructo mecânico ainda se baseiam na concepção dualista entre mente e corpo derivada do método cartesiano. Certamente, Descartes possibilitou uma nova concepção de saúde, que, vinculada ao Renascimento e a toda a revolução artístico-cultural a partir do século XVI, passou a considerar outros fatores causadores da doença para além de uma concepção puramente religiosa. Além da decomposição fragmentária (análise) instituída pelos estudos de Descartes, seus achados contribuíram significativamente para o avanço da Medicina no tratamento de doenças e afecções que afligiam a condição humana.

Por outro lado, Espinosa se refere à importância do ambiente e do afeto para o pensamento, entendendo que nossas afecções - isto é, as impressões que os outros corpos e ideias nos causam - geram em nós afetos, sentimentos que influem em nosso modo de ver o mundo, estar no mundo, relacionarmo-nos, pensarmos, conhecermos, valorarmos as coisas (MARTINS, 2004) e, nessa instância, compreender que as emoções influenciam no humor, no corpo e na própria saúde.

Sobre isso, Ayres (2007) afirma que não basta apenas fazer o outro falar sobre aquilo que um profissional de saúde afirma que é relevante saber. É preciso também ouvir o que o outro, que demanda o cuidado, tem a dizer. Que ambos saibam colocar os recursos técnicos existentes a serviço dos sucessos práticos almejados em conjunto. Gadamer (2011) afirma que a perturbação da saúde é o que torna necessário o tratamento médico, mas que parte de um tratamento é 
o diálogo, que representa a dimensão decisiva de toda atividade médica (ou de qualquer profissional da saúde). $\mathrm{O}$ diálogo promove a humanização da relação entre uma diferença fundamental, a que há entre profissional de saúde e paciente.

A orientação do pensamento gadameriano amplia a reflexão na medida em que afirma sobre a necessidade dos sujeitos estarem abertos e dispostos ao diálogo na interatividade do ouvir e falar. Assim, a possibilidade do entendimento é determinada pela abertura que a compreensão e a escuta vão proporcionando ao diálogo. Na relação médico-paciente, por exemplo, a coerção social legitimada pela razão médica coloca o profissional como condutor do diálogo, o que anularia a motivação do entendimento, pela “inferiorização” que a relação hierárquica provoca através da condição ouvinte e falante.

Entre o relativismo (subjetividade levada à última instância) e a determinação externa de possibilidades de entendimentos (Conceito da OMS, Carta de Ottawa, Lei no 8.080, entre outras), a amplitude de compreender o que "é” saúde ainda é algo que ocorre fora de si. Certamente, sente-se mais e vive-se mais sobre saúde do que pensamos e discursamos sobre ela (a linguagem humana está imersa em limites, sem poder tudo dizer).

Frente a esse diálogo, Ayres (2007) aponta que, quando recorremos ao termo doença, na linguagem ordinária, já nos colocamos numa área de discursividade construída com base no ideal biomédico. Novamente, a fragmentação acaba sendo incorporada ao discurso, mesmo que não se perceba. Sobre isso, o autor alerta que, na discursividade biomédica, o que preocupa é a profunda assimetria entre a legitimidade que confere aos discursos causal-controlistas e outras construçôes discursivas relacionadas às experiências vividas de saúde e doença.

A compreensão que o colaborador Salgueiro tem sobre a formação em saúde é salientada pelas experiências dos estudantes ainda na formação inicial. $\mathrm{O}$ colaborador observa que:

[...] a formação atual está mais ampla e ela está com maior integralidade. Quando me formei, eu não tinha essa vivência que os alunos têm, [...] não tinha essa integração das matérias dentro do próprio curso, e também não tinha essa preocupação em ter relação com as demais cadeiras, os demais cursos [...] hoje, vejo os alunos tendo uma aproximação muito maior dentro da faculdade com o que é a realidade atual, com o que eles vão encontrar quando se formarem, com essa visão mais holística, mais humanista, mais generalista, que a gente aprendeu fazendo, depois de formada e diferente de hoje, que eles já têm esse contato dentro do curso. 
Cabe destacar a percepção que os colaboradores vão apresentando, na medida em que refletem sobre a formação em saúde, articulando as experiências que tiveram durante seu próprio processo de formação, e como percebem a formação atualmente enquanto docentes. Isso representa um movimento dos processos de formação, e, nessa perspectiva, as questôes tratadas no ensino refletem-se de forma direta ou tangencial nos conhecimentos que direcionam as intervençôes pedagógicas na formação inicial contemporânea.

De acordo com o relato de Figueira, na mesma medida em que percebemos algumas transformações na formação em saúde nos dias de hoje, também podemos perceber dificuldades para a construção de uma percepção mais robusta sobre o tema da saúde na universidade. Muitas vezes, devido a algumas regras e obrigaçôes institucionais, acaba sendo reduzida a possibilidade de aprofundar o reconhecimento sobre saúde. Sobre isso, Figueira argumenta:

[...] há um limite quando a gente tem uma grade curricular a cumprir. Então, a gente tem uma carga horária exigindo que você aborde muitos temas, uma ementa enorme [...], às vezes, você não consegue fazer um debate com os alunos, 'hoje de manhã a gente vai sair e vai caminhar na comunidade, vai olhar as potencialidades, o território', não dá tempo para isso, porque você tem um ementário para dar conta. Então, acho que a gente anda muito nessa grade, grade mesmo, porque você se torna preso um pouco, naquilo que você tem que dar conta, e os cursos estão sendo avaliados por isso. Então, tem o ENADE [Exame Nacional de Desempenho dos Estudantes], e a gente acaba ficando nessa política; não é uma questão só institucional, é do governo também, e isso limita um pouco.

Mesmo reconhecendo as dificuldades referentes ao processo de qualificação conceitual, devido a demandas significativas, o exemplo citado sobre a aula não se refere a questões conceituais, mas sim a reconhecimento de território, esforço certamente importante e necessário. Pensar o escopo deste texto remete à necessidade de se recuperar a importância de qualificarmos nossas construções conceituais, como possibilidade de qualificar nossa inserção no mundo.

Nessa seara, em concordância com Rezer (2010), essas preocupaçōes e questionamentos permitem considerar a possibilidade de pensar as relações entre o trabalho docente nos processos de formação e o mundo do trabalho no contexto das construções curriculares. Aqui, percebemos uma possibilidade significativa de qualificar e explicitar perspectivas teóricas assumidas coletivamente. Se o desafio de pensar/fazer currículo não pode ser tratado de forma idealizada, romântica, 
como se fosse possível, através dele, "resolver" dilemas construídos ao longo da modernidade, tal empreitada parece se manifestar como uma possibilidade de ação que possibilita a qualificação de nossas concepções.

Assim, partindo dos diálogos realizados com os colaboradores, percebemos um esforço perante a superação da concepção de saúde vinculada à "ausência de doenças". Por outro lado, percebemos também que as referências de um modelo biomédico ainda se encontram enraizadas no imaginário de determinados discursos. De nossa parte, compreendemos esse movimento dialético como parte de um processo de qualificação de possibilidades de compreensão de mundo, uma espécie de momento entre um "não mais" (modelo biomédico) e um "ainda não" (uma projeção de mundo ainda não passível de objetificação mais concreta). $\mathrm{Ou}$ seja, estamos em meio a um momento muito fecundo para a discussão proposta nesta investigação.

Em síntese, as contribuições dialética e hermenêutica fundamentadas pelo debate entre Habermas e Gadamer ganham sentido na discussão proposta, na medida em que compreendemos a possibilidade da comunicação pelo entendimento da linguagem através do agir comunicativo e da fusão de horizontes. No entanto, as pretensões habermasiana e do pensamento gadameriano sobre o conhecimento, embora diferentes, nos permitem entender possíveis concepções de saúde como uma obra social, coletiva, edificada pelo diálogo entre diferentes saberes, o que implica transformá-la em algo cujos significados são sempre passíveis de reconstrução.

A compreensão sobre esses processos possibilita ampliar a capacidade de reflexão sobre os processos pedagógicos na ES, ressaltando a necessidade de uma racionalidade comunicativa no mundo dos sujeitos que compõem esse contexto. Nessa direção, a educação se dá como uma fusão de horizontes que eleva nossas perspectivas de mundo a outros patamares, não mais apenas nossa ou de nossos interlocutores, mas de ambos. Levar a sério essa pretensão é radicalizar o processo de ensinar e de aprender como instância privilegiada da condição humana no mundo.

\section{A importância de discussões conceituais como referência para intervenção...}

Dialogar sobre espaços e tempos específicos para discussões de ordem conceitual acerca da temática da saúde representa um tema que acabou surgindo nos discursos 
produzidos pelos colaboradores. Estes entendem que esse empreendimento deveria

ser realizado na forma de atividades que transcendam os espaços tradicionais da sala de aula. Consideram, ainda, que esse esforço se desdobraria na melhoria da qualidade da formação e do próprio serviço de saúde. É importante destacar que a discussão sobre a relação teoria e prática se manifestou de forma bastante evidente nos discursos pertinentes a esse tema.

De acordo com o relato de Copaíba, discutir sobre concepções de saúde poderia auxiliar "na mudança dos pré-conceitos que temos sobre o próprio significado de saúde". Certamente, percebe-se uma noção de pré-conceitos bastante enraizada na noção contemporânea (iluminista). Cabe lembrar que, sob uma perspectiva gadameriana, qualquer compreensão começa pelos preconceitos, influenciados por uma tradição específica, na medida em que vamos nos desenvolvendo em um tempo histórico específico, gerando significados frente aos possíveis fatores que permitem qualificar a discussão sobre saúde. Por outro lado, a afirmação de Copaíba é pertinente, porque se refere à possibilidade de que diálogos acerca desse tema possam contribuir com a qualificação de nossa percepção de mundo, ou seja, nossos pré-conceitos.

Como enfatizado por Buriti, as discussōes em saúde contribuiriam para a compreensão de que há concepções limitantes, segundo ela, atreladas ao "modelo flexneriano" . Para transcender tal modelo, entende que é necessário compreender o processo histórico pelo qual se constrói/construíram diferentes percepçôes, refletindo sobre os retrocessos e reconhecendo os avanços. A ideia de movimento presente no discurso de Buriti representa um importante argumento que evidencia a importância do diálogo na construção do conhecimento.

Porém, lembrando Habermas (1990), as coerções de ordem política e epistemológica acabam por colaborar com a colonização do mundo da vida (Lebenswelt) pelo sistema e determinam as orientações, nesse caso, no trabalho docente, através de legislações, reduzindo a possibilidade de comunicação no processo de formação.

As dificuldades que os docentes encontram para ampliar a discussão sobre saúde estão relacionadas, em parte, aos aspectos políticos e operacionais institucionais, o que dificulta a articulação entre os próprios docentes. A discussão é colocada geralmente como uma iniciativa de ordem individualizada. Aqui cabe resgatar a necessidade de as instituições de ensino superior possibilitarem 
espaços de discussão aos seus docentes, constituindo coletivamente dispositivos que possibilitem a qualificação por meio do diálogo embasado teoricamente. $\mathrm{O}$ empoderamento se dá em meio ao diálogo assumido pelos protagonistas que se colocam nessa condição.

Sobre isso, Jacarandá ressalva que "não só discutir dentro do espaço da universidade, mas discutir no serviço de saúde, nos grupos onde a gente pertence [...] pela questão da própria definição de saúde, hoje em dia, ampliada”. Defende, ainda, o papel importante da universidade na motivação da circularidade da discussão em saúde: "o primeiro movimento tem de vir da universidade, a universidade refletir e ter um alicerce, um estímulo para que isso aconteça (cursos para capacitação de professores, rodas de diálogos, debates). E eu vejo que o Pró-Saúde é o lugar para que a gente faça isso".

Embora reconheça na universidade a responsabilidade em "dar o primeiro passo", o discurso remete à necessidade de ampliar os espaços de interlocução inclusive para o serviço de saúde. O que percebemos é que, se na universidade questôes como as que ora trouxemos ainda são pouco potencializadas, no serviço de saúde, abrir espaços formais de discussão sobre questóes conceituais representa horizonte ainda mais distante.

A importância em discutir sobre concepções de saúde também é referida por Figueira, ao refletir sobre: "como a gente vai lidar com isso [...] se eu não discuto, se eu não amplio essa minha percepção e essa minha concepção, eu também vou ser um profissional mais limitado." Nesse sentido, o referido distanciamento entre percepção e concepção, noções bastante comuns naquilo que convencionamos denominar "Área da Saúde", fundamentada tradicionalmente sobre questôes dicotômicas (saúde/doença, teoria/prática,...), se desdobra muitas vezes nas intervenções dos profissionais de saúde. Com isso, investir em tempos e espaços para promover a discussão de temáticas na formação inicial é possivelmente contribuir para qualificar os discursos produzidos no campo da saúde.

Sem reduzir a discussão à noção de causa e efeito, entendemos que o empoderamento frente a questôes conceituais possibilita uma ampliação de leitura de mundo, o que não deixa incólumes nossas perspectivas sobre a intervenção profissional.

Outro aspecto evidenciado no discurso dos colaboradores foi o de que as responsabilidades frente às iniciativas de organização de espaços coletivos 
para discussões conceituais, via de regra, acabam sendo debitadas na figura do professor. Ou seja, ele é que "deveria" providenciar esses espaços e tempos de discussão, desonerando a instituição dessa responsabilidade. Nesse caso, o excesso de atividade, o descuido frente à discussão proposta, ou mesmo o descomprometimento profissional representam entraves para muitos docentes. Rezer (2010) destaca que, em muitas universidades, os professores se veem obrigados a cumprir uma alta carga horária de ensino de disciplinas em sala de aula, o que dificulta ou inviabiliza condições de trabalhar com atividades de estudo e qualificação. Aqui, é possível resgatar a ideia de que diferentes condições objetivas se edificam em diferentes instituições de ensino superior, de acordo com as possibilidades e limitações de cada espaço. Contudo, a intensificação do trabalho docente é um fenômeno já estabelecido na educação básica e em ampla ascensão na educação superior.

Ypê, ao considerar a importância de espaços e tempos para discussão sobre saúde, reflete que "gostaria que alguns conceitos fossem discutidos como área e não como curso específico." Logo, a qualificação da formação docente a partir da interlocução entre diferentes "faculdades" representa um fator primordial nesse processo. Ainda argumenta que:

\footnotetext{
[...] qualificar algumas questões, desmistificar essa ideia de que tudo é prática e que o que é conceitual, o que é mais social, as antropologias, as sociologias, os contextos sociais, a discussão de meio ambiente, são menos ou são mais que os processos técnicos. Discutir saúde a partir das questōes sociológicas e entender que, a partir de cada contexto isso pode oferecer formas diferentes de atuar e que fará diferença.
}

Nesse sentido, Gadamer (2011) sinaliza que a tensão entre saber teórico e saber prático, que se encontra no centro da questão tratada, é, por seu lado, sempre vencida por este, na medida em que a ciência faz também com que a política de implementação na respectiva área seja tratada como ciência aplicada. A mais alta representação daquilo que designamos como técnica possui esse caráter de ser ciência aplicada. No entanto, Gadamer refere que a tensão não desaparece com isso, mas sim aumenta, e que quanto mais intensamente a área de aplicação é racionalizada, mais falta o próprio exercício do juízo e, com isso, a experiência prática no sentido de experiência de mundo. Habermas (1989) destaca que as limitações da razão instrumental, nesse sentido, "questōes moral-práticas do tipo 'o que devo fazer?'” são afastadas da discussão racional, na medida em que 
não podem ser respondidas do ponto de vista da racionalidade - sob a lógica cronológica de um início, meio e fim.

Concordando com Gadamer (2011, p. 34), controlar a aplicação daquele nosso "ser-capaz-de-fazer", possibilitado cientificamente, não é tarefa da ciência, mas permanece como uma tarefa da política. O saber prático modificase na medida em que o próprio saber prático do ser humano se torna objeto da ciência. Esta já não é uma ciência que seleciona como objeto de sua pesquisa o próprio ser humano: ela acolhe como objeto, antes, o saber do ser humano de si mesmo, transmitido pela tradição histórica e cultural. Aqui talvez esteja o salto de que necessitamos.

Nesse sentido, a prática pedagógica na formação inicial no campo da saúde se constitui historicamente por conteúdos que parecem compreender questôes teóricas e práticas como polarizações. Certamente, a compreensão sobre o que é teoria e o que é prática determina que tipo de interpretação pode ser perspectivada na relação saúde-doença.

Sobre isso, Carvalho afirma que "a teoria dá base para a prática. A prática é a forma da gente também 'testar' a teoria, mas eu não posso aprender a teoria e depois ir só testar e não posso deixar só para fazer a prática e depois voltar para estudar, tem que ser um permanente diálogo uma inter-relação entre as duas".

A partir da fala de Carvalho, podemos identificar a circularidade que move o conhecimento e as tensões entre teoria e prática. A ressignificação que o diálogo permite gerar entre ambas permite a continuidade das açôes, que não se findam, mas se complementam a partir de novos elementos que sustentam essa intrínseca dinâmica. Nesse caso, lembrando Marques (2003), a teoria nega a prática em seus imediatismos e a prática nega a teoria descolada do mundo. Assim, as percepçôes de mundo se fundem em uma organicidade que insistimos em não reconhecer. Nessa circularidade, brotam os sentidos que emergem desse movimento e que produzem valia diante das situações humanas no mundo da vida.

A partir dos elementos abordados, evidencia-se a dificuldade de adentrar com maior densidade as condições que determinam as noçōes de teoria e prática. De acordo com o diálogo apresentado pelos colaboradores, muitas das açōes descritas são permeadas pelas dificuldades encontradas para ampliar e qualificar a discussão sobre saúde. Investir na discussão sobre teoria e prática parece representar uma boa síntese para as questões ora evidenciadas. 
Uma possibilidade seria repensar as potencialidades da ação comunicativa, que pode ser fortalecida por espaços institucionalizados que permitam a reflexão, os encontros entre docentes e as reuniōes pedagógicas, criando assim, momentos institucionalizados que proporcionem novas articulaçôes e possibilitem um contexto no qual a interação social tenha peso maior do que as ações resultantes da tecnocracia e da burocratização. Essas oportunidades de diálogo contribuiriam com a possibilidade dos colaboradores de lidarem com suas próprias convicçōes, ressignificando e qualificando o próprio trabalho docente.

\section{Concepção de saúde expressa nos projetos dos cursos de graduação e do Pró-Saúde: compreensões e interpretações docentes...}

Considerando a necessidade de adequação ao novo modelo assistencial da saúde pública, a preocupação acerca da formação profissional tem aumentado, no sentido de que os profissionais deem conta de atender às proposições do SUS.

De acordo com Ypê, que está há oito anos envolvida diretamente com o PróSaúde, a concepção de saúde expressa no Projeto Pedagógico (PP) do seu curso de origem tem a ver com os ditames da Constituição Federal (art. no 196) e da VIII Conferência Nacional de Saúde (1986), que apontam para os determinantes sociais e também para a capacidade de agir do sujeito.

No que se refere às concepções de saúde expressas no Pró-Saúde, Ypê fundamenta a compreensão, apontando que "é o conceito de saúde que está expresso nas políticas, ou na política de saúde do país, que é o da Constituição Federal, VIII Conferência Nacional de Saúde”. Assim, acaba articulando os conhecimentos do Pró-Saúde nas intervenções aproximando-se de algumas discussões e experiências, conforme exemplifica a seguir:

\footnotetext{
[...] discutimos a diferença do parto na comunidade indígena e na não indígena, o quanto a cultura não indígena interferiu nisso, o quanto que essa mescla de cultura fez diferença. Muitos dos índios, hoje, querem ter o bebê no hospital, mas alguns dos índios não querem ter bebê no hospital e a gente não permite que eles tenham lá, na aldeia ou na comunidade indígena. Problematizar isso com os estudantes tem a ver com um conceito de saúde.
}

A fala de Ypê se refere a um tema pouco evidenciado nas diferentes áreas da saúde: o choque entre culturas - no caso específico desse exemplo, diferentes tradições historicamente construídas por diferentes comunidades sobre algo que denominamos saúde. De nossa parte, entendemos que a saída para impasses dessa 
ordem seria o diálogo, algo sempre complexo. De acordo com Habermas (1989), todo diálogo contém um elemento de dominação, pois se nem todos sempre têm a mesma chance de falar, é a dominação que permite a ação do sujeito dominador.

Chamamos a atenção nesse ponto para a incompletude de toda e qualquer cultura. A fusão de horizontes como possibilidades de sínteses provisórias representaria um esforço digno da complexidade do exemplo. Dessa fusão poderiam surgir sínteses entre os sujeitos, em tese, com pretensões a alçar níveis mais elaborados de compreensão de mundo.

Habermas (1989) defende a utilização prática de "dispositivos institucionais" a fim de "compensar" os eventuais desequilíbrios existentes na ação comunicativa, visto que (I) os discursos estão submetidos às limitaçôes do espaço e do tempo e têm lugar em contextos sociais; (II) os participantes de argumentações são movidos por outros motivos além da busca cooperativa da verdade; e (III) os temas e as contribuiçōes têm que ser ordenados, as relevâncias asseguradas e as competências avaliadas. São necessários dispositivos institucionais a fim de neutralizar as limitaçōes empíricas e as influências externas e internas inevitáveis, de tal sorte que as condições idealizadas, já sempre pressupostas pelos participantes da argumentação, possam ser preenchidas pelo menos numa aproximação razoável.

Ao observarmos as referências teóricas presentes nas falas dos colaboradores, podemos perceber que há limitações preocupantes. As questôes de ordem conceitual são retratadas de forma tímida, e os discursos estão mais vinculados àquilo que poderíamos chamar de "questōes operacionais", baseadas especialmente em cartas e leis. Como apontamos, estas são referenciais importantes, mas insuficientes.

Vale lembrar, porém, o esforço dos colaboradores em destacar que trabalham com uma noção "ampliada" de saúde. Certamente, caberia refletir sobre o que significa classificar um conceito como ampliado. Como os colaboradores entendem esse conceito? Aqui, percebemos questóes que as entrevistas deveriam ter abordado. Enfrentá-las, sem dúvida, requer um olhar complexo para os determinantes do processo saúde-doença, na direção de trabalhar a formação profissional a partir dos eixos da promoção da saúde, visando à formação de um sujeito crítico, participativo e reflexivo, capaz de intervir diante desses determinantes numa perspectiva dialógica. 
Tendo em vista as mudanças no que se refere ao ensino superior, os colaboradores apresentam argumento em consonância com Chiesa et al (2007), que afirmam que as mudanças estão orientadas para a elaboração de currículos integrados, orientados por competências, articulados aos diversos setores da sociedade e desenvolvidos em ambientes propícios ao aprendizado. Neles, os sujeitos envolvidos são valorizados e o que se pretende é a construção do conhecimento, a partir da realidade vivenciada, o que qualifica a formação para o trabalho em saúde. Novamente a questão do currículo emerge com veemência como possibilidade de compreender melhor os caminhos de nossa própria caminhada.

Como lembra Rezer (2010), compreender melhor nosso próprio trabalho significa compreender melhor o mundo em que vivemos. Diante disso, apontamos para a necessidade de avançar e melhorar nossos debates, aproximando as interfaces dos diferentes conhecimentos que compõem o campo, possibilitando a atuação de professores capazes de discutir criticamente suas próprias intervenções.

É possível perceber nas falas dos colaboradores, acentuadamente, a questão da individualização como um componente problemático. Contraditoriamente, ao apresentar no discurso a importância de um conceito ampliado de saúde, os colaboradores fazem referência, mesmo que não percebam, à noção de responsabilização do próprio docente frente aos desafios da docência. Discutir sobre concepções de saúde depende dos esforços dos envolvidos, que não podem fugir das responsabilidades frente aos diferentes desafios que se apresentam. Porém, há questôes como as que evidenciamos neste artigo, por exemplo, a de que somente pelo diálogo poderíamos produzir enfrentamentos.

Nessa instância, apontamos para a necessidade do diálogo como possibilidade de qualificarmos nossas próprias compreensões de mundo. Como afirma Ayres (2007), um diálogo é essencialmente uma interação aberta. O curso de um diálogo pertence tanto a seus interlocutores quanto estes pertencem àquele. Se há diálogo, é porque há mais o que saber, é porque há mais a se dizer.

Em vista do que foi discutido até então, Rezer faz uma ressalva importante sobre a intensificação do trabalho docente na Educação Superior (2010). Talvez essa condição se reflita no pequeno espaço para discussão sobre o tema da saúde nos diferentes cursos que compõem o Pró-Saúde na Unochapecó, sem dúvida, um paradoxo de difícil solução. Nesse caso, entendemos que um processo de 
discussōes sistemáticas sobre saúde poderia permitir uma ampliação da presença desse tema no interior dos cursos, algo que, pela fala dos colaboradores, não é dinâmica sistemática na agenda dos docentes.

Segundo Gadamer (1997), a compreensão deve ser pensada menos como uma ação da subjetividade do que como uma participação em um evento da tradição, um processo de transmissão no qual passado e presente são constantemente mediados. $\mathrm{O}$ momento da compreensão indica um caráter próprio, no qual há uma interação entre intérprete e tradição. Essa compreensão pressupõe, dessa forma, uma relação dos horizontes da tradição e do intérprete, a qual, para Gadamer, é uma 'fusão de horizontes', e que se torna uma possibilidade para refletir sobre a ação dos docentes e sobre o que estes compreendem sobre saúde, com possíveis desdobramentos para o seu trabalho. Nesse sentido, também a ação comunicativa possibilitaria repensar a prática pedagógica para além da razão instrumental, através do que Habermas denomina "razão comunicativa".

\section{Considerações finais}

Discutir sobre concepções de saúde não é uma ação regular na prática docente na educação superior. Isso foi percebido ao longo dos discursos apresentados pelos colaboradores, evidenciando a dificuldade na elaboração de argumentos sobre temas presentes no cotidiano da formação inicial, bem como no do serviço em saúde.

As concepções de saúde apresentadas pelos colaboradores estão fortemente vinculadas à noção de bem-estar e às referências da OMS, da Carta de Ottawa (e outras cartas de promoção da saúde), da Constituição Federal Brasileira e das políticas implementadas pelo Ministério da Saúde. Nessa direção, podemos concluir que elas têm influenciado significativamente o discurso docente nesse campo do conhecimento.

Isso tem proporcionado a referência conceitual central para o desenvolvimento das intervençōes nos diferentes espaços da formação inicial. Por um lado, tratase de um avanço; por outro, vem obliterando a importância de discussōes mais profundas sobre a complexidade dos temas abordados neste estudo.

Outro aspecto a evidenciar é a forte tradição cartesiana identificada nas falas dos colaboradores, o que pode, em certa medida, alimentar a dificuldade encontrada de compreensões mais ampliadas de saúde. Ou seja, o modelo 
cartesiano ainda é referência do modelo biomédico, que vincula o conhecimento na educação superior de maneira muito impactante.

No entanto, há um esforço nas falas dos colaboradores quando referem o reconhecimento do sujeito e expressam que a realidade influencia a condição de saúde-doença. Esse pensamento contemporâneo está presente, inclusive, nas orientações das Diretrizes Curriculares Nacionais (DCN), que abordam compreensões mais amplas sobre a percepção do sujeito e seu entorno nas relações de mundo, considerando diferentes culturas, políticas, realidades econômicas, sociais e ambientais sobre a condição de saúde do sujeito.

As discussões sobre saúde ocorrem especialmente nos espaços de intervenção do Pró-Saúde, o que sinaliza a importância dessa proposta. Nos cursos e na universidade, as discussões se resumem, muitas vezes, a questões operacionais, especialmente assuntos mais "imediatos". Também ficou evidente a preocupação dos colaboradores com questôes relacionadas ao cumprimento de uma alta carga horária de trabalho, o que permite pensar sobre a intensificação do trabalho docente como um dos elementos que prejudicam discussões de ordem teórica.

Sobre como vem ocorrendo o debate acerca de concepções de saúde no cotidiano de intervenção dos colaboradores no ensino superior, percebemos que raramente é possível a discussão sobre saúde, já que, institucionalmente não há espaços oficiais que permitam a reflexão, tal como ocorre no Pró-Saúde, por exemplo. A própria dicotomia saúde-doença apresentada em alguns discursos dos colaboradores e a dificuldade em discursar sobre teoria e prática podem fornecer subsídios sobre como se constroem as relações no âmbito da reflexão sobre o conhecimento no campo da saúde.

No entanto, as aproximações e distanciamentos das concepções de saúde dos colaboradores e as referências orientadoras de saúde do Pró-Saúde demonstraram que a compreensão das reformulações das DCN possibilitou aos colaboradores discursar através de um conceito ampliado de saúde, incentivando uma formação baseada no perfil do egresso para as necessidades do SUS. É importante destacar o esforço dos colaboradores em ampliar sua concepção de saúde, em demonstrar que entendem saúde como algo mais do que ausência de doença. Mas para isso, avançam pouco para além dos horizontes do SUS.

Dessa forma, a aproximação da Filosofia no campo da saúde nos ajuda a compreender sobre o que acontece no cotidiano. Não a esgotar a reflexão, mas a 
tensionar sentidos e significados, realizando "um passo atrás" frente às questões de mundo, interpretando e reinterpretando-as para que os pressupostos não sejam postos como "verdades absolutas".

Para finalizar, é oportuno recuperar uma questão importante, balizadora de muitos momentos desta investigação: O que é saúde? Na impossibilidade de uma resposta que esgote a questão, já que se trata de um fenômeno inapreensível, faz-se necessário qualificar nosso horizonte do perguntar, sem esperar resposta peremptória. Esse esforço evidencia a finitude humana como balizadora de possíveis respostas que qualifiquem nossa capacidade de lidar com tema de tamanha complexidade. Qualquer resposta definitiva frente a uma questão como essa só pode ser da ordem do transcendental metafísico. Felizmente, nossas pretensões não são dessa monta. Nosso esforço se coloca na condição de compreender melhor o conhecimento do conhecimento, a partir de uma postura hermenêutica de suspeita frente à naturalização do mundo ${ }^{2}$

\section{Referências}

AYRES, R. Uma concepção hermenêutica de saúde. Physis: Rev. Saúde Coletiva. Rio de Janeiro, v. 17, n. 1, p. 43-62, 2007.

CHIESA, A. et al. A formação de profissionais da saúde: aprendizagem significativa à luz da promoção da saúde. Cogitare Enfermagem, v. 12, nov. 2007.

GADAMER, H-G. Verdade e método I: traços fundamentais de uma hermenêutica filosófica. Petrópolis: Vozes, 1997.

. O caráter oculto da saúde. Petrópolis: Vozes, 2011.

HABERMAS, J. Consciência moral e agir comunicativo. Rio de Janeiro: Tempo Brasileiro, 1989. O discurso filosófico da modernidade. Lisboa: Pub. Dom Quixote, 1990.

LAWN, C. Compreender Gadamer. Petrópolis: Vozes, 2010. 208 p.

MARQUES, M. O. A formação do profissional da educação. Ijuí: Unijuí, 2003.

MARTINS, A. Filosofia e saúde: genealógico e filosófico-conceitual. Cad. Saúde Pública, Rio de Janeiro, v. 20, n. 4, p. 950-958, 2004.

MINAYO, M. C. S. O desafio do conhecimento: pesquisa qualitativa em saúde. 12. ed. São Paulo: Hucitec, 2010. 407 p.

PAGLIOSA, F. L.; DA ROS, M. A. O Relatório Flexner: para o bem e para o mal. Revista Brasileira de Educação Médica, v. 32, n. 4, p. 492-499, 2008. 
REESE-SCHÄFER, W. Compreender Habermas. 3 ed. Petrópolis: Vozes, 2008.

REZER, R. O trabalho docente na formação inicial em Educação Física: reflexões epistemológicas... Tese (Doutorado em Educação Física) - Programa de Pós-Graduação em Educação Física, Universidade Federal de Santa Catarina,. Florianópolis, 2010.

\section{Notas}

${ }^{1}$ Em 1910, foi publicado o estudo "Medical education in the United States and Canada - a report to the Carnegie Foundation for the advancement of teaching", que ficou conhecido como o Relatório Flexner (Flexner Report). É considerado o grande responsável pela mais importante reforma das escolas médicas de todos os tempos nos Estados Unidos da América (EUA), com profundas implicaçōes para a formação médica e diferentes áreas vinculadas à saúde, em escala mundial. "A força de seu relatório deve-se à natureza abrangente, em termos numéricos, da sua avaliação, à ênfase sobre as bases científicas e, em grande parte, ao fato de ter sido dirigido primariamente ao grande público" (PAGLIOSA; DA ROS, p. 493, 2008). Abraham Flexner (Louisville, Kentucky, em 13/11/1866) visitou as 155 escolas de Medicina dos EUA e Canadá durante seis meses. Com base nas avaliações que fez, publicou seu famoso relatório. O que Flexner propõe é a instalação de uma nova ordem para a reconstrução do modelo de ensino médico: as escolas médicas devem estar baseadas em universidade, e os programas educacionais devem ter uma base científica (ibidem). A seu modo, representou uma revolução no ensino da medicina, sustentando-se até hoje como referência explícita ou tácita para diferentes campos do conhecimento. Baseados em uma perspectiva hermenêutica, não desconsideramos as contribuições de Flexner; porém, entendemos que o modelo cientificista de tratar a formação em saúde mostra seus limites como nunca antes.

${ }^{2}$ A. C. Stanga participou da concepção e planejamento do estudo, análise e interpretação dos dados, elaboração do rascunho e revisão crítica do conteúdo. R. Rezer participou da elaboração do rascunho, revisão crítica do conteúdo e da aprovação da versão final do manuscrito. 


\section{Conceptions of health, teaching work and the Pró-Saude: the paths of hermeneutics...}

This research aimed to understand the health concepts that guide the work of organizing teachers within the PróSaúde. The theoretical and methodological approaches were put in perspective from a hermeneutic orientation. Field work included contributions of eight teachers of the Pró-Saúde II Unochapecó. The instrument used was one semi-structured interview. The interpretive process was prepared from the foundation of hermeneutics Gadamer and Habermas and grounded on the thematic analysis proposed by Minayo. Health concepts identified are strongly linked to welfare notion. References with which the employees work in daily life are: Documents of the World Health Organization, the Ottawa Charter, the Brazilian Federal Constitution and the policies implemented by the Health Ministry's directives of Pro-Health, according to the employees, allowed to discuss more properly the concept of extended health, which favors, to a certain extent, the systematization and organization of teaching interventions for the effectiveness of initial training in health. So more than "setting" or showing one or a few concepts of health, we understand that the most important is to keep open the discussion on the "health sense" with which we act with others in different intervention processes.

Key words: hermeneutics; health concepts; Pró-Saúde. 